\title{
Modern Learning Theories Provide Applications For Distance Learning Practice
}

Dana V. Tesone, University of Central Florida

Denver Severt, University of Central Florida

Monica L. Carpenter, University of Central Florida

\begin{abstract}
This article reports the findings of a recent empirical study that was conducted at a large university in the United States. The study compared the findings from modern learning theories to reported perceptions of undergraduate and graduate students taking courses in online learning environments. The intention of the study was to compare perceived student learning preferences with theories that support distance learning design and delivery. The article provides a report of objectives, methodology, findings, discussion, conclusions, and implications relative to the study. Final suggestions concerning online courses aimed at satisfying student learning expectations are implicated from the findings of the study.
\end{abstract}

Keywords: distance learning, learning theories, higher education

\section{INTRODUCTION}

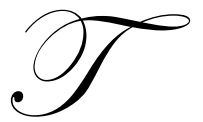

he article presents findings from a recent study that centered on distance learning design and delivery methods for instructors. The authors begin by presenting evidence from the literature in the discipline of education to support four selected learning theories. These theories appear to support distance learning delivery methods. The article then presents a comparison of those theoretical constructs with findings in the distance learning literature. The purpose of this comparison is to determine the extent of compatibility between findings from the social sciences and those discovered through practical pedagogical applications. Next, the authors use the combined evidence to support a single theoretical model of learning that is conducive to distance learning course design and delivery techniques. The article tests this model from the standpoint of distance learning activities through a preliminary empirical process. The authors conclude the article with practical implications for those educators engaged in distance learning activities.

\section{SELECTED LEARNING THEORIES}

It may be argued that learning theories extend back to the time of Socrates. Written theories emerged in the western world during prior centuries through the works of individuals such as Dewey and Piaget (Dewey, 1895). Since that time, numerous modern learning theories have emerged in evolutionary fashion through the use of investigative techniques associated with the social sciences. There are four relatively modern theories in existence that seem to lend nicely to the pedagogy associated with distance learning methods. These include: Cognitive Flexibility Theory, Dual-Coding Theory, Elaboration Theory, and Transactional Distance Theory. It would seem appropriate to provide a brief description of each of the four theories.

All of the theories could fall within the domain of Learning Constructivism, an overriding concept that suggests learners 'construct' their own meaning as part of the learning processes. Two common themes within the domain include meta-learning (thinking about learning) and the belief that knowledge is defined as meaning attributed by the learner to the content matter (Hein, 1991). 
The objective of Cognitive Flexibility Theory is for learners to understand the interconnection of content knowledge areas within 'complex' areas of intended learning (Godalk, Harvey \& Moller, 2001). Learning outcomes associated with the theory would encourage 'open thinking' and avoid 'oversimplification of subject knowledge (Spiro et al, 1987, 1988, 2003). The technique associated with the theory suggests a series of ideas, analytical perspectives, and delivery designs to facilitate multiple perspectives concerning the knowledge content (Lima, Koehler \& Spiro, 2004). One study suggests that the approach may be used to bring forth realistic problem situations that represent experiential bases used to exercise analytical skills and reinforce the content of knowledge (Jonassen, 1997).

In a study that experimented with the use of 'criss-crossed' text, as compared with linear logical layout, the researchers found the latter to produce better results on reproductive memory tests (Jacobson and Spiro, 1991). Certain theorists consider knowledge sets that include high degrees of variation from case to case to be 'illstructured' (Jones and Spiro, 1992). If this is true, certain professional disciplines, such as the field of management consists of practices that would be considered by the theorists to be ill-structured by nature, in that there is no single correct approach to solving a specific management problem. However, the point is well taken to add as much linear logic to the presentation of knowledge topics and foster open thinking in terms of solving relevant associated problems in these courses.

Dual Coding Theory is also referred to as dual processing for learning. It suggests that two systems (verbal and nonverbal) comprise working memory of learned knowledge (Mayer, 1999). The systems are connected and when both are used in parallel fashion information processing may be maximized by the learner (Paivio, 1990). This concept argues for multi-modal (multiple senses) instructional methods to be used in course development and delivery (Gellevij, van der Meij, de Jong \& Pieters, 2002). One study reported that visual cues (pictures) are processed in working memory faster than text or verbal cues (Presno, 1997). It has also been reported that nonverbal (visual) and verbal (auditory and text) codes work in tandem to produce heightened awareness levels among learners (Sadoski, Getz \& Rodriguez, 2000). This theory seems to support the use of combined visual, auditory and kinesthetic modes of instruction to appeal to all learning styles.

Elaboration Theory is focused on course design and somewhat overlaps the tenets contained within Cognitive Flexibility Theory in that it advocates a simple-to-complex approach in developing instruction modules (Chou, 1999). Elaboration Theory also touches upon the content of Dual Coding theory by advocating a double learning process consisting of knowledge expansion and then condensation (Reigeluth and Stein, 1983). Elaboration Theory has been applied to the work of courseware designers who use hypertext tags to highlight pertinent information within online courses (English and Reigeluth, 1996). The theory advocates the use of simplified examples to increase the production of instruction (Spector and Davidsen, 1998). One study argues that the theory facilitates high levels of learner performance in response to generalized questions as a result of learning various aspects of a given reading (Reder, 1980). Similar to the other theories, Elaboration Theory suggests the use of succession strategies for delivering varied content orientations within a course.

The theory of Transactional Distance poses direct implications for OLE course designers. It articulates the concepts of interaction (transactional) and autonomy (distance). The theory suggests that increased levels of learner autonomy will result in improved learning abilities (Stein, et al, 2005). Advocates of the theory focus on course structure, dialogue and autonomy and suggest that a balance should be created among the variables to facilitate learning within a course (Kanuka, Collett \& Caswell, 2002). One study identified four categories of exchange between learners and course content, course interfaces, other learners, and instructors in online courses (Chen, 2001). It is suggested that the categories represent the 'scope' of the course, which should be balanced with the variables of structure, dialogue and autonomy. At this point the discussion of the four theories is complete.

There appears to be a recurring theme of 'duality' that runs through each of the four selected learning theories. Cognitive Flexibility combines linear text models with experiential learning scenarios. Dual Coding suggests parallel processing of verbal and nonverbal stimuli. Advocates of Elaboration Theory recommend providing course content expansion and then condensation of the same concepts. Finally, Transactional Distance argues the case of balance between exchange and autonomy. It is possible that the theme of duality might have been 
observed by instructional faculty engaged in the design and development of courses provided in online learning environments (OLE).

\section{DISTANCE LEARNING}

Over recent years, thousands of campuses have experimented to some extent with distributed learning methods using electronic communication tools for course delivery (Schneider and Germann, 1999; Kalamatianou and McClean, 2003). Innovators from training programs in the areas of engineering and computer science began working with such initiatives during the 1980s through the use of telecommunication interfaces requiring some level of technical proficiency on the part of each user. Early adopting educators in the fields of business and nursing were attracted to web-based distributed education modalities during the proliferation of public Internet access that began in the middle 1990s (Lyytinen and Rose, 2003). Today, most traditional training and education institutions intend to use Online Learning Environments to provide some level of course delivery. This has also sparked the interests of researchers in the discipline.

A vast body of distance learning literature has emerged over recent years (Schrum, 2002). This could suggest that these programs have achieved "mainstream" status in many academic institutions. A number of studies address issues such as faculty compensation, incentives, course evaluation, and pedagogy in online learning environments. It is commonly reported that the shift from traditional teaching to OLE requires 'change' on the part of the instructor. It is likely that the concept of change may serve as both a catalyst and a cause of resistance on the part of educators based on varied perceptions concerning OLE instruction. One study suggests that online education has created a new paradigm, which has fostered new modes of learning that involve innovative views of pedagogy and requires internal change on the part of participating faculty members (Rahman, 2001).

Journal articles addressing the issues of pedagogy and OLE began to appear in the literature during the latter 1990s (Rimmington, 1999). It was predicted that the frequency of such contributions would continue to escalate into the new millennium (Cho, 2000), which does seem to be the situation today. While a number of established learning theories have been reported within the context of OLE initiatives; there are limited contributions that combine learning theories within the context of direct applications of distance learning techniques. The four theories may be combined with the distance literature findings to present a theoretical construct for designers and instructors engaged in OLE activities.

\section{A LEARNING MODEL}

\section{Learning Process Model}

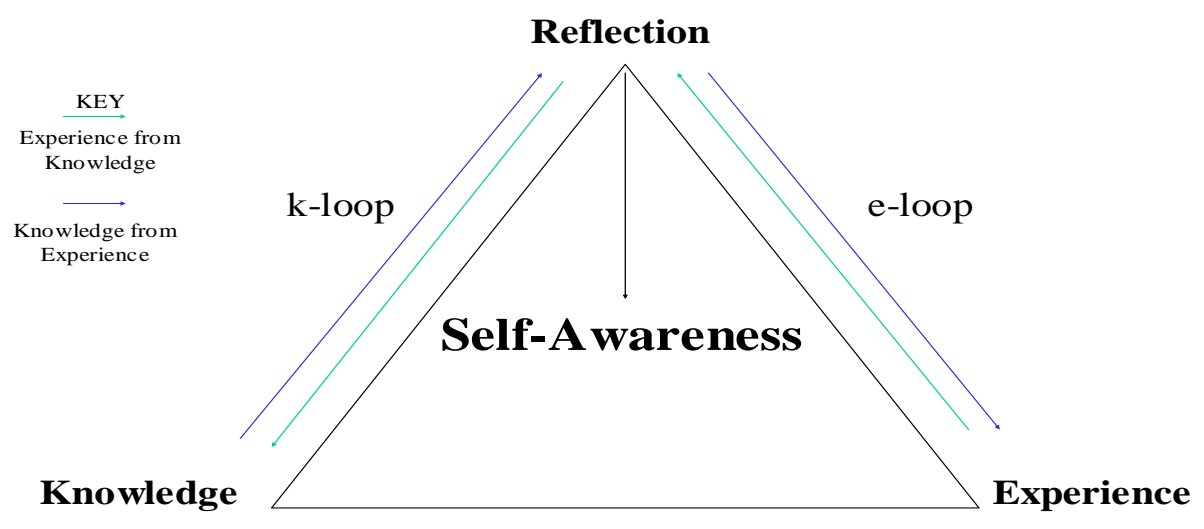

Figure 1 
Based on the information presented so far, it is possible to determine a working model of learning processes for business management courses. A holistic model would serve the learning processes associated with traditional classroom as well as OLE coursework. The patterns of duality identified in the learning theory literature seem to suggest a dual learning process in models describing actual learning practices. This would seem to be particularly true for courses that teach a professional practice, such as management. The two aspects of teaching courses in this field involve knowledge and practical skills. The learner must assimilate content knowledge, and then apply that knowledge in an industrial setting. An experiential learning approach might be appropriate for this type of learning. Figure 1 provides a description of a learning process that would satisfy the criteria of the literature and serve the learning system of a business management program.

The triangle represents two types of learning by the arrows that originate at the top, and then loop through the bottom and return to the upper point for infusion into self-reflection concerning what was learned. An experiential learning loop moves in a clockwise direction from the right-to-left sides of the triangle, in which an individual practices a function then assimilates information about the function and returns to a state of reflection. An aware individual who works in a professional position on a regular basis would acquire experiential learning over time. In this instance, the individual gains 'knowledge from experience.'

Conversely, a knowledge loop (k-loop) reverses this order by functioning in a counter-clockwise fashion (left-to-right) around the triangle (knowledge, then experience) to return to the reflective state. When working adults who possess years of experience return to school to earn a degree, they bring the experiential representations with them. Hence, the k-loop automatically triggers these experiential representations and the knowledge becomes grounded through prior and current experiences. A single loop learning process is usually sufficient in this environment. This is not the case with more traditional age learner cohorts.

Traditional learners in business management programs require two loops of learning to blend knowledge with experience. The k-loop is used to deliver content knowledge. In the absence of experience, the content will appear in the abstract to the learner. Once the new knowledge is memorized by rote, there could be time for reflection about the new knowledge. Next, the instructor will invoke the e-loop by creating an experiential scenario in which the learner identifies with the experience in the first-person. Another pause for reflection will permit the learner to assimilate the blended knowledge and experiences. The brain will store the experiences as if they happened in real life for aided recall when the learner is faced with a similar situation as a practitioner. This pendulum process is repeated throughout each module of a management course. Does this process satisfy the criteria of the selected learning theories?

The knowledge loop is a serial process and it leads to an experiential component which satisfies the criteria associated with the Cognitive Flexibility theory. The verbal and nonverbal learning cues purported by the Dual Coding theory are also satisfied by the two learning loops, particularly if the instructor implements multimodal communication techniques. The course knowledge is delivered in a progressive fashion, resulting in the expansion of the knowledge base and the experiential aspect condenses the knowledge into a small number of scenarios, which seems consistent with the Elaboration model. Finally, the learner engages in interactive exchanges during both kloop and e-loop learning, while autonomously pausing for reflection at the end of each cycle. This would satisfy the balance requirement of the Transactional Distance approach to learning. It would be appropriate to test the application of the model and the learning theories with a preliminary study. It could be anticipated that students will show agreement that various course design factors are important for effective learning.

\section{THE STUDY}

The purpose of the study was to determine levels of agreement among student perceptions that aspects of course design and delivery related to the 4 theories were important facilitators of learning. A self-administered questionnaire was completed by a convenience sample of 113 students at a large U.S. university. The questionnaire asked a total of sixteen questions using a five-point Likert-type scale. The question categories were arranged by each of the 4 learning theories. Three questions dealt with Cognitive Flexibility Theory, five questions dealt with Dual Coding Theory, four questions dealt with Elaboration Theory, and four questions dealt with Transactional 
Distance Theory. Questions were anchored by 5 being strongly agree, 4 being agree, 3 being neutral, 2 being disagree and 1 being strongly disagree.

The sample included respondents who were enrolled in 4 online classes. Two senior level capstone classes were completely web-based with no seat time. The other two classes were graduate courses employing a mixedmode format that combined seat time with online interaction. Respondents in the undergraduate group represented a traditional age cohort that ranged from 19-to-22 years. The older graduate students comprised a small proportion of the sample that contributed just 14 of the total 113 completed useable surveys. The sampling method was appropriate for the purpose of the study.

\section{RESULTS}

The data were analyzed for simple means totals among all four groups and among all item attributes in each theory group (see Table 1). Dual Coding had a reported mean of 4.21, Cognitive Flexibility had a reported mean of 3.81, Elaboration Theory had a reported mean of 4.16 and Transactional Distance had a reported mean of 3.85.

Table 1: Means and Standard Deviations with Total Group Means

\begin{tabular}{|c|c|c|c|}
\hline Question & Mean & $\begin{array}{c}\text { Std. } \\
\text { Deviation }\end{array}$ & $\begin{array}{l}\text { Group } \\
\text { Mean }\end{array}$ \\
\hline Dual Coding Theory & & & 4.21 \\
\hline Students learn best from seeing, hearing and doing tasks surrounding the information. & 4.45 & .760 & \\
\hline Students learn from both verbal and nonverbal learning systems. & 4.43 & .778 & \\
\hline Most students process pictures and words differently. & 4.26 & .823 & \\
\hline Most students will remember pictures for a long time. & 4.01 & .701 & \\
\hline Most students have dominant visual and/or hearing learning styles. & 3.90 & 1.04 & \\
\hline Cognitive Flexibility Theory & & & 3.80 \\
\hline Realistic problem situations are presented in discussions and the text. & 4.09 & .922 & \\
\hline Students do better on tests that have limited variation among concepts. & 3.73 & 1.07 & \\
\hline $\begin{array}{l}\text { Students perform better on tests that examine memory of concepts that follow a straight } \\
\text { line of logic. }\end{array}$ & 3.58 & 1.05 & \\
\hline Elaboration Theory & & & 4.10 \\
\hline $\begin{array}{l}\text { Students learn best when things are presented as simple concepts and then progress in } \\
\text { terms of complexity. }\end{array}$ & 4.45 & .824 & \\
\hline Realistic problem situations are presented in discussions and the text. & 4.09 & .922 & \\
\hline Students prefer simplified examples of the concepts. & 4.08 & 1.01 & \\
\hline $\begin{array}{l}\text { Students learn best when things are presented as simple concepts and then progress in } \\
\text { terms of complexity. }\end{array}$ & 3.80 & .857 & \\
\hline Transactional Distance Theory & & & 3.85 \\
\hline Students like to choose their own ways of learning content. & 4.17 & .865 & \\
\hline $\begin{array}{l}\text { A well structured online course with high levels of dialogue makes students feel like they } \\
\text { are part of things. }\end{array}$ & 3.87 & .964 & \\
\hline $\begin{array}{l}\text { Online students prefer to learn from course content and other students, as opposed to just } \\
\text { the instructor. }\end{array}$ & 3.79 & 1.06 & \\
\hline Students like high levels of course structure. & 3.58 & 1.10 & \\
\hline
\end{tabular}

All items were measured on a 5-point Likert type scale (5-strongly agree, 1-strongly disagree) 


\section{IMPLICATIONS FOR BUSINESS EDUCATORS}

A practical implication for business management educators is that the themes presented within the four theories may be condensed into a simple model of learning for use by instructors to design courses. The knowledge loop represents serial delivery of content that may be expanded and contracted at the instructor's discretion. The delivery of knowledge could employ both verbal and nonverbal representations. The experiential loop would be used to reinforce content learning through interactivity. Again this process would include verbal and nonverbal representations. The reflection process provides learner autonomy as a process to develop personalized depictions of both knowledge and experiential representations.

Another implication for educators is that traditional age cohort learners require a double learning loop of knowledge to experience then experience back to knowledge with reflective pauses at the top of each loop. This is not the case for adult learners with work experience. An instructor may successfully employ a single knowledge learning loop process with this cohort, knowing that the experience base already exists for knowledge application. The instructor needs only to provide methods for interactivity to share these existing experiences for reinforcement and possibly provide assignments based on reflective practices.

A final implication is that one sample of online students perceived that practices associated with the 4 theories were important for learning. This is not to suggest generalizability, as that portion of the study was merely intended to survey students from a single convenience sample. However, there are implications for future research to test broader arrays of student perceptions for the purpose of identifying preferences for online learning methods associated with various learning theories.

\section{CONCLUSION}

Most business educators focus on areas of specialized research. It is not feasible to expect them to be conversant in the area of learning theories in addition to being experts in their fields. However, those educators with teaching assignments might be assumed to have an interest in providing effective learning delivery, regardless of the course modality. Hence, it seems logical that the provision of condensed models based on learning theories poses value for these educators. Such contributions to the literature provide 'maps' to assist educators with course design and delivery. This may be particularly true for those instructors who are newly embracing the foray into distance learning delivery methods.

\section{REFERENCES}

1. Chen, Y.-J. (2001). Transactional distance in world wide web learning environments. Innovations in Education and Teaching International, 38(4), 327-338.

2. Cho, W. (2000). Just-in-time education: Tools for hospitality managers of the future?; International Journal of Contemporary Hospitality Management, Bradford. 12, (1). 31-40.

3. Chou, C. (1999). Devloping hypertext-based learning courseware for computer networks: the macro and micro stages. IEEE Transactions on Education, 42(1), 39-44.

4. Dewey, J. (1895). Selected writings. In R.D. Archambault (Ed.), John Dewey on education: Selected writings, New York: Random House.

5. English, R.E. \& Reigeluth, C.M. (1996). Formative research on sequencing instruction with the elaboration theory. Educational Technology Research \& Development, 44(1), 23-42.

6. Gellevij, M., van der Meij, H., de Jong, T., \& Pieters, J. (2002). Multimodal versus unimodal instruction in a complex learning context. The Journal of Experimental Education, 70(3), 215-239.

7. Godshalk, V. M., Harvey, D.M., \& Moller, L. (2004). The role of learning tasks on attitude change using cognitive flexibility hypertext systems. The Journal of the Learning Sciences, 13(4), 507-526.

8. Hein, G.E. (October, 1991). Constructivist learning theory. CECA Conference Proceedings: Jerusalem.

9. Heinemann, M. H. (2005). Teacher-student interaction and learning in online theological education, part II: additional theoretical frameworks. Christian Higher Education, 4, 277-297. 
10. Hodes, C. L. (1990). The Induction Use and Effectiveness of Mental Imagery as an Instructional Variable, Pennsylvania State University.

11. Hodes, C. L. (1994). Processing visual information: implications of the dual code theory. Journal Of Instructional Psychology, 21(1), 36-43.

12. Jacobson, M. J., \& Spiro, R.J. (1991). Hypertext learning environments and cognitive flexibility: characteristics promoting the transfer of complex knowedge in L. Birnbaum (Ed.). The International Conference on the Learning Sciences, Charlottesville, VA, Associaiton for the Advancement of Computing in Education, 240-248.

13. Jones, R. A., \& Spiro, R. (1992). Imagined conversations: The relevance of hypertext, pragmatism, and cognitive flexibility theory to the interpretation of "classic texts" in intellectual history in (Ed.). ACM ECHT Conference Proceedings, Milano, Italy: ACM Press, 141-148.

14. Jonassen, D.H. (1997). Instructional design model for well-structured and ill-structured problem-solving learning outcomes. Educational Technology Research and Development 45(1), 65-95.

15. Kalamatianou, A.G. \& McClean, S. (December, 2003). The perpetual student: Modeling duration of undergraduate studies based on lifetime-type education data. Lifetime Data Analysis. Boston. 9(4). 31113.

16. Kanuka, H., Collett, D. \& Caswell, C. (2002). University instructor perceptions of the use of asynchronous text-based discussion in distance courses. The American Journal of Distance Education, 16(3), 151-167.

17. Lally, V., \& Barrett, E. (1999). Building a learning community on-line: Towards socio-academic interaction. Research Papers in Education, 14(2), 147-163.

18. Lima, M., Koehler, M.J., \& Spiro, R.J. (2004). Collaborative interactivity and integrated thinking in Brazilian business schools using cognitive flexibility hypertexts: the panteon project. Journal of Education Computing Research, 31(4), 371-406.

19. Lyytinen, K. \& Rose, G.M. (December, 2003). The disruptive nature of information technology innovations: The case of Internet computing in systems development organizations. MIS Quarterly. Minneapolis. 27(4). 557-63.

20. Mayer, R. E. (1999). Designing instruction for constructivist learning in C. M. Reigeluth (Eds.), Instructional-Design Theories and Models Volume II: A New Paradigm of Instruction Theory. Hillsdale, NJ: Erlbaum.

21. Mayer, R. E., \& Sims, V.K. (1994). For whom is a picture worth a thousand words? Extensions of a dualcoding theory of multimedia learning. Journal of Educational Psychology, 86(3), 389-401.

22. Moore, M. G. (1973). Towards a theory of independent learning and teaching. Journal of Higher Education, 44(9), 661-679.

23. Moore, M. G. (1991). Theory of distance education in (Ed.). Second American Symposium on Research in Distance Education, May 22-24, The Pennsylvania State University, University Park, PA.

24. Moore, M. G., \& Kearsley, G. (1996). Distance Education: A Systems View. Belmont, CA: Wadsworth.

25. Paivio, A. (1990). Mental representations: A dual coding approach. New York: Oxford University Press.

26. Presno, C. (1997). Bruner's three forms of representation revisited: action, pictures, and words for effective computer instruction. Journal Of Instructional Psychology, 24(2), 112-118.

27. Rahman, M. (2001). Faculty Recruitment Strategies for Online Programs. Journal of Distance Learning Administration. IV (IV). Accessed from the www: http://www.westga.edu/ distance/ojdla/winter44/rahman44.html

28. Reder, L. M. (1980). The role of elaboration in the comprehension and retention of prose: a critical review. Review of Educational Research, 50(1), 5-53.

29. Reigeluth, C. M., \& Stein, F.S. (1983). The elaboration theory of instruction in C. M. Reigeluth (Eds.), Instructional Design Theories and Models: An Overview of Their Current Status. Hillsdale, NJ: Lawrence Erlbaum: 335-382.

30. Richardson, J. T. E. (2003). Dual coding versus relational processing in memory for concrete and abstract words. European Journal of Cognitive Psychology, 15(4), 481-509.

31. Rimmington, M. (1999). Vocational education: Challenges for hospitality management in the new millennium. International Journal of Contemporary Hospitality Management, Bradford. 11, (4). 186-191.

32. Sadoski, M., Goetz, E.T., \& Rodriguez, M. (2000). Engaging texts: effects of concreteness on comprehensibility, interest and recall in four text types. Journal of Educational Psychology, 92(1), 85-95. 
33. Schneider, S.P. \& Germann, C.G. (Winter, 1999). Technical communication on the Web: A profile of learners and learning environments. Technical Communication Quarterly. 8(1). 37-48.

34. Schrum, L. (2002) Dimension and Strategies for Online Success: Voices from Experienced Educators. Journal of Asynchronous Learning Networks. 6(1/6). Accessed from the www: http://www.aln.org/alnweb/journal/Vol6_issue1/6_1schrum.htm

35. Spector, J. M., \& Davidsen, P.I. (1998). Constructing learning environments by using dynamics. Journal of Courseware Engineering, 1, 5-11.

36. Spiro, R. J., Collins, B.P., Thota, J.J., \& Feltovich, P.J. (2003). Cognitive flexibility theory: hypermedia for complex learning, adaptive knowledge application, and experience acceleration. Educational Technology, 43(5), 5-10.

37. Spiro, R. J., Coulson, R.L., Feltovich, P.J., \& Anderson, D. (1988). Cognitive flexibility theory: advanced knowledge acquisition in ill-structured domains. in (Ed.). Tenth Annual Conference of the Cognitive Science Society, Hillsdale, NJ, Lawrence Erlbaum, 375-383.

38. Spiro, R. J., Vispoel, W.L., Schmitz, J., Samarapungavan, A., \& Boerger, A. (1987). Knowledge acquisition for application: cognitive flexibility and transfer in complex content domains. in B. C. Britton, \& S. Glynn (Eds.), Executive control processes. Hillsdale, NJ: Lawrence Erlbaum Associates.

39. Stanton, N. A., Porter, L.J., \& Stroud, R. (2001). Bored with point and click? Theoretical perspectives on designing learning environments. Innovations in Education and Teaching International, 38(2), 175-182.

40. Stein, D. S., Wanstreet, C.E., Calvin, J., Overtoom, C., \& Wheaton, J.E. (2005). Bridging the transactional distance gap in online learning environments. The American Journal of Distance Education,(19), 2.

41. Van Patten, J., Chao, C-I., \& Reigeluth, C.M. (1986). A review of strategies for sequencing and synthesizing instruction. Review of Educational Research, 56(4), 437-471. 